\title{
Chapter 3 \\ Risk Factors of Labor-Market Insertion for Children of Immigrants in Switzerland
}

\author{
Andrés Guarin and Emmanuel Rousseaux
}

\subsection{Background and Research Questions}

In the decades after World War II, the massive influx of temporary immigrants, which was in response to a lack of workers, resulted in a large number of immigrants to most Western European countries (Coleman 2006; Mens 2006). The children of these immigrants are commonly called the second generation (Crul 2004). Their characteristics include being educated and socialized in the host country. In Europe, early research on employment for children of immigrants started in the 1990s with studies that specifically targeted this population (Bader and Fibbi 2012; Crul 2008). These early works were heavily influenced by theories that were developed in the United States. Early theories, such as Park's and Gordon's theories on linear assimilation and Gans's theory of generations, have given way to Portes and Zhou's critical theory of segmented assimilation (Rea and Tripier 2003). The theory of linear assimilation suggests that the difficulties experienced by first-generation immigrants tend to disappear in successive generations. In this sense, immigration is considered a process of assimilation that progressively allows the structural integration of later generations. By contrast, the theory of segmented assimilation

\footnotetext{
A. Guarin $(\bowtie)$

Life Course and Inequality Research Centre (Lines), University of Lausanne,

Lausanne, Switzerland

National Centre of Competence in Research LIVES - Overcoming Vulnerability: A Life course perspectives (NCCR Lives), Lausanne, Switzerland

e-mail: Andres.guarin@unil.ch

E. Rousseaux

Institute of Demography and Socioeconomics, University of Geneva, Geneva, Switzerland

National Centre of Competence in Research LIVES - Overcoming Vulnerability: A Life course perspectives (NCCR Lives), Lausanne, Switzerland

e-mail: Emmanuel.Rousseaux@unige.ch
}

C. Bolzman et al. (eds.), Situating Children of Migrants across Borders and

Origins, Life Course Research and Social Policies 7,

DOI 10.1007/978-94-024-1141-6_3 
(Portes and Zhou 1993) assumes that several factors can have an impact on this process, including the quality of training (academic and professional), the substitution of the old wave of immigration with new waves, and the economic conditions. This perspective then postulates that certain groups of second-generation children remain marginalized even as others are successfully integrated. ${ }^{1}$

Today, the children of immigrants represent a large group of inhabitants in the urban areas of Western Europe and the United States: "the large size of the second generation guarantees that these individuals will have a profound impact on the cultural and ethnic differences within their societies" (Crul and Mollenkopf 2012:3). However, research on these populations shows that social and ethnic origins still strongly determine the life course of the second generation, particularly in terms of education and training; these origins also impact these populations' transition into the labor market (Portes et al. 2005; Lagana 2011). Specifically, Reisel et al. (2012) showed that the most marginalized minorities experience the greatest difficulties in Western European and US cities.

The study of the second generation is especially interesting in the specific case of Switzerland. Indeed, the successive massive migrations starting at the end of World War II led to Switzerland's population having a multicultural composition, with a large and growing number of residents who are the children of immigrants. To a certain extent, these children of immigrants from various countries make up the current social structure of Switzerland (Wanner 2004).

\subsubsection{Second-Generation Residents'Access to the Labor Market}

The transition from childhood to adulthood is characterized by a change in behaviors from those of teenage life to a series of adult roles (Gauthier 2007). Authors have identified at least four dimensions that mark the transition from youth to adulthood: (1) leaving the parental home, (2) forming a family, (3) participating in civic life, and (4) accessing the labor market (Andréo 2001). Getting a job is clearly an essential element of personal autonomy. It generally allows financial independence and contributes to self-esteem and peer recognition (Avenel 2006). Successful access to the professional world is a primary way to accumulate resources. Most researchers agree, however, that the transition to the labor market is sensitive to individual differences (Billari and Liefbroer 2010; Dahinden 2005; Gauthier 2007; Settersten 2005). This transition is considered to be a turning point in life. Indeed, it is at this point that social inequalities can combine with latent vulnerabilities, such

\footnotetext{
${ }^{1}$ Alba et al., quoted by Crul and Mollenkopf (2012), outlined three different approaches that scholars use to analyze the process of acculturation to the host country among immigrants and their children; this includes assimilation, integration, and cohesion. According to the authors, each of these approaches is commonly used to understand the differences between natives and the immigrant population. They also defend the idea that contextual differences must be considered to understand the life courses of immigrant children.
} 
as a lack of resources (especially concerning education), to cause a young person difficulty in finding a job.

Access to employment also has consequences regarding immigrants' integration in society. Active participation in the labor market is essential to ensure social cohesion and empowerment for both immigrants and their children. In most Organization for Economic Co-operation and Development (OECD) countries, immigrants recorded worse difficulties than non-immigrants on the labor market. They generally suffered from a higher unemployment rate. ${ }^{2}$ Most studies have found that firsttime immigrants face both cultural adaptation challenges regarding identity and relationships (Canales 2000; Kevisto 2001; Levitt 2004; Portes 1997, 1999; Vertovec 2003) and economic problems (Alba 1985; Portes 1994) in the host country. Portes (1997) showed that first-time immigrants must mobilize resources that lead them to diversify their work trajectories and family lives more strongly than natives of the host society do. Children of immigrants generally exceed their parents in terms of labor-market status, occupational achievement, and economic status (Farley and Alba 2002). The increasing trend toward higher attainment in education is more important for second-generation residents than for natives (Telhado and Tavares 2000). Still, it is interesting to compare employment status and occupational achievement among second-generation residents and natives. Indeed, native-born people and the immigrants' children who have been educated and socialized in the host country follow fairly similar professional career trajectories. However, a series of studies have shown that the second generation remains in a disadvantaged position in several European countries (Heath et al. 2008). For example, Crul (2008) showed that, in France, second-generation young adults of Turkish and Moroccan descent are more likely to (1) drop out of school, (2) achieve lower educational levels, and (3) have a lower job status than their majority-group peers. Simon (2003) found the same results, showing that second-generation residents from Maghreb are disadvantaged in the French labor market. However, for some immigrant groups, the assimilation process is much better. For example, the families of immigrants from Mexico to the United States experienced considerable improvements through three generations, narrowing the educational and income gaps between themselves and native-born whites (Perlman and Waldinger 1997). In a similar way, in Switzerland, second-generation residents of Italian and Spanish descent generally experience less difficulty in getting a job than either their parents or their native counterparts do (Fibbi et al. 1999; Bolzman et al. 2003).

One of the main explanations for the differences in educational and professional success between children of immigrants and natives is related to the parents' social status. Numerous studies have shown that inequalities are partly rooted in the social origin of the parents, especially their education level and their socio-professional status. Of course, parents with higher education levels will be able to provide help during their children's schooling, but "they also have experience with the more demanding educational pathways, and this strategic knowledge places them [their children] in an advantageous position at important educational transitions" (Kristen et al. 2011:124). Nevertheless, these authors found that, after controlling for social origin, inequalities

\footnotetext{
${ }^{2}$ Note that large differences exist among immigrant groups.
} 
persist. Heath et al. (2008) showed that, for certain groups of immigrant children, there is an ethnic penalty regarding the transition to the labor market.

\subsubsection{Second-Generation Residents in Switzerland}

Switzerland has an important history of immigration. At the end of World War II, many immigrants from Italy and Spain came to Switzerland. Bilateral agreements with these countries governed the entry and residence of these temporary guest workers and facilitated their settlement in Swiss society. Later, workforces from Portugal and from the Balkans joined these immigrant groups (Fibbi et al. 2007). According to the Swiss Federal Statistical Office, in 2012, about one-third of the total population had an immigrant origin. ${ }^{3}$ Four-fifths of the people with immigrant origins were of the first-generation immigrants, and the remaining one-fifth were of the second generation (Bader and Fibbi 2012).

A study conducted on the children of Spanish and Italian immigrants to Switzerland mentioned that, "in terms of training and professional integration, there is very little difference between young Spanish and Italian immigrants and Swissborn belonging to working classes or lower middle classes" (Bolzman 2007). The intergenerational relationships among those of Spanish and Italian origin were more intense than those among the Swiss lower-middle classes. Furthermore, the services exchanged between generations were more numerous within immigrant families, which became an advantage during the young people's transitions to work and family lives (Bolzman 2007).

However, some other immigrant populations that are now highly represented in Switzerland, such as Turks or Albanians, show different trends. Several studies have shown that second-generation residents with these origins are more likely to experience difficulties during their transitions to adulthood than are children of immigrants of other nationalities or native-born residents of the Swiss lower-middle class (Fibbi et al. 2005, 2010a; Wanner 2004). Fibbi et al. (2004), who experimented with the "practice testing" methodology that was standardized by the International Labour Organization, showed that employers, when treating job applications, discriminated strongly against young men with Turkish or Yugoslavian origins; a last name that does not sound European counts as a negative point for employers.

\subsubsection{Research Questions}

In this chapter, we focus on unemployment among second-generation residents during their transition to the labor market in Switzerland. Based on the definitions presented in the Introduction and Chap. 2 of this volume, we define

\footnotetext{
${ }^{3}$ http://www.bfs.admin.ch/bfs/portal/fr/index/themen/01/07/blank/key/04.html
} 
second-generation residents as individuals (1) whose parents are immigrants and (2) who were born in Switzerland or moved to Switzerland before 10 years old. ${ }^{4}$ Using the Swiss Labor Force Survey (SLFS) data, we address four research questions. First, we want to assess whether second-generation residents are more successful on the labor market than first-generation immigrants (RQ1). Although this question has already been extensively studied in many countries, we want to provide more insight in the specific case of immigrants to Switzerland; second, we want to assess whether second-generation residents experience more difficulties than Swiss natives do (RQ2). Indeed, research in other countries supports the idea that those in the second generation often are more disadvantaged than are natives in terms of occupational and educational achievement; those in the second generation also have a higher risk of unemployment (Heath and Cheung 2007). Third, we want to assess whether the father's educational level has an impact on his children's ability to find employment (RQ3). Using a decision-tree-based preliminary analysis (Sect. 2.4), we succeeded in refining this hypothesis by highlighting an interaction effect between fathers' and children's education: Although educated young adults find employment because of their own grades, the education of the father could be an important resource for lesseducated young adults. Finally, we want to know if there is a specific "ethnic penalty" for particular groups of immigrants' children (RQ4). With this question, we seek to confirm the results obtained in other countries, which demonstrated that second-generation residents of Turkish or Kosovar origin (and those from surrounding countries) experience more difficulties in getting a job than Swiss natives do (Crul 2008; Fibbi et al. 2004; Simon 2003).

\subsection{Data and Methods}

\subsubsection{Data}

This study is based on SLFS data. The aim of the SLFS is to provide data to study the evolution of employment and unemployment in Switzerland. It collects information on different aspects of working conditions and on the consequences of the free movement of persons. Due to strict compliance with International Labor Organization standards, the Swiss data are comparable with those of the OECD

\footnotetext{
${ }^{4}$ This definition is based on the work of Oropesa and Nancy (1997) and on the introduction and Chap. 2 of this volume. We decided to use the term "second generation" and not " 1.5 generation." Indeed, previous investigations that distinguished between children who arrived in Switzerland between 6 and 15 years old and those born in Switzerland showed no significant differences. (Note that this could be explained by the small number of respondents that arrived in Switzerland at these ages.) We chose to take the upper limit of 10 years old for the age of arrival and to combine the interviewees who matched this criteria with immigrants' children who were born in Switzerland. Both types of respondents share the fact that they were socialised in the Swiss obligatory school. We use the term "second generation" to designate this combined population. The term "first generation" designates immigrants who settled in Switzerland after 10 years old.
} 
countries and the European Union. The Swiss Federal Statistical Office has conducted the SLFS since 1991, and it targets permanent residents in Switzerland who are age 15 and older. This database has two characteristics that are of foremost interest in our research. First, since 2003, an additional sample of foreign residents has been added to the standard sample. This feature of SLFS overcomes the problem of small sample size that generally affects surveys of immigrant populations or other minorities. This additional sample was taken from the Système d'Information Central sur la Migration.

The SLFS is a rotating panel..$^{5}$ Each year, a different module in the questionnaire is devoted to specific issues. In 2009, the Federal Statistical Office included a module on "further training" and "the entry of young people into the labor market" as a complement to the standard survey. In this study, we are especially interested in the "immigration" module, from which we can identify second-generation residents. This module questions respondents about their social origins (e.g., their parents' education) and about their geographical origins (and those of their parents). This module was integrated into the core questionnaire in 2001, 2003, 2008, and 2009.

However, it should be noted that second-generation residents are underrepresented in the 2001 survey (which occurred before the sample of foreigners was added in 2003), so we decided not to consider this wave. To maximize the number of cases for analysis, we built our sample by pooling all the waves from 2003 through $2011 .^{6}$

\subsubsection{Sample}

Because we are interested in transitions to the labor market, our sample includes only those individuals between 15 and 35 years old who have entered the workforce; all students are dropped. We select individuals who participated in the survey at least once between 2003 and 2011. We also consider the participants' up-to-date employment status during the 2003-2011 observation window. The SLFS provides employment status for each year during this period. Therefore, we set the employment status for each respondent as the most recent available employment from this window. ${ }^{7}$ The second generation is distinguished from the first generation according

\footnotetext{
${ }^{5}$ From 1991 to 2009, people were interviewed once per year (in the second quarter) over a 5-year period. Since 2010, the SLFS sample is a 4 -wave rotating panel, with a 3 -month period between the first and second interviews, a 9-month period between the second and third interviews, and a 3-month period between the third and fourth interviews. Thus, participants are interviewed four times over 15 months.

http://www.bfs.admin.ch/bfs/portal/en/index/infothek/erhebungen__quellen/blank/blank/ enquete_suisse_sur/uebersicht.html.

${ }^{6}$ As a consequence, following the Swiss Federal Statistical Office, we chose not to use nonresponse weights in our analyses, as no official weights are provided for this kind of design.

${ }^{7}$ The code used for extracting the employment status for each individual in each year (and the corresponding values of the covariates) is included in the Rsocialdata package (Rousseaux et al. 2013). This makes our analyses replicable.
} 
to the criteria of birth and age, as we defined above. To determine the country of origin of second-generation residents, we considered the parents' place of birth. To allow clearer interpretations, we dropped individuals whose parents did not have the same country of origin. The distribution of our sample is presented in Table 3.1 for the first generation and in Table 3.2 for the second generation.

The plurality of the immigrants' children in the sample are of Italian or Spanish origin (36.77\%); $16.18 \%$ are Kosovar (or from the surrounding countries). We also note in our data that, for the first generation, the most represented group is the immigrants from Kosovo and surrounding countries (20.36\%).

\subsubsection{Variables}

\subsubsection{Dependent Variable}

The SLFS divides employment status into four categories: employed, apprentice, unemployed, and non-active. By sample construction, this variable represents the most up-to-date employment status during the 2003-2011 observation window. As we are interested in individuals who are unable to find employment, we derived the dependent variable "unemployment" from this variable by recoding as follows: "yes" = unemployed and "no" = employed or apprentice. "Non-active" individuals are dropped from our analyses in this chapter.

\subsubsection{Independent Variables}

We first considered the country of origin. We sorted individuals into 6 groups based on country of origin: (1) Switzerland, (2) Italy or Spain, (3) Portugal, (4) Turkey, (5) Kosovo and surrounding countries, ${ }^{8}$ and (6) other European countries. ${ }^{9}$ Indeed, as these groups have different migration origins, we expect that they will behave differently when they access the labor market. Because we want to assess the impact of individual resources, the educational level of both the respondents and their fathers are of great interest. We also considered investigating the educational level of the mothers, but this covariate contained too many missing values to be considered in our analyses. Both types of educational level are coded in three categories (high, intermediate, and low). As our selected population is between 15 and 35 years old, educational level can evolve with time. To be consistent, for each individual, we used the educational level from the same year as that person's most up-to-date employment status.

\footnotetext{
${ }^{8}$ We also included individuals from the countries surrounding Kosovo (Albania, Macedonia, Montenegro, and Serbia).

${ }^{9}$ We merged all European countries that did not have a specific migration wave.
} 


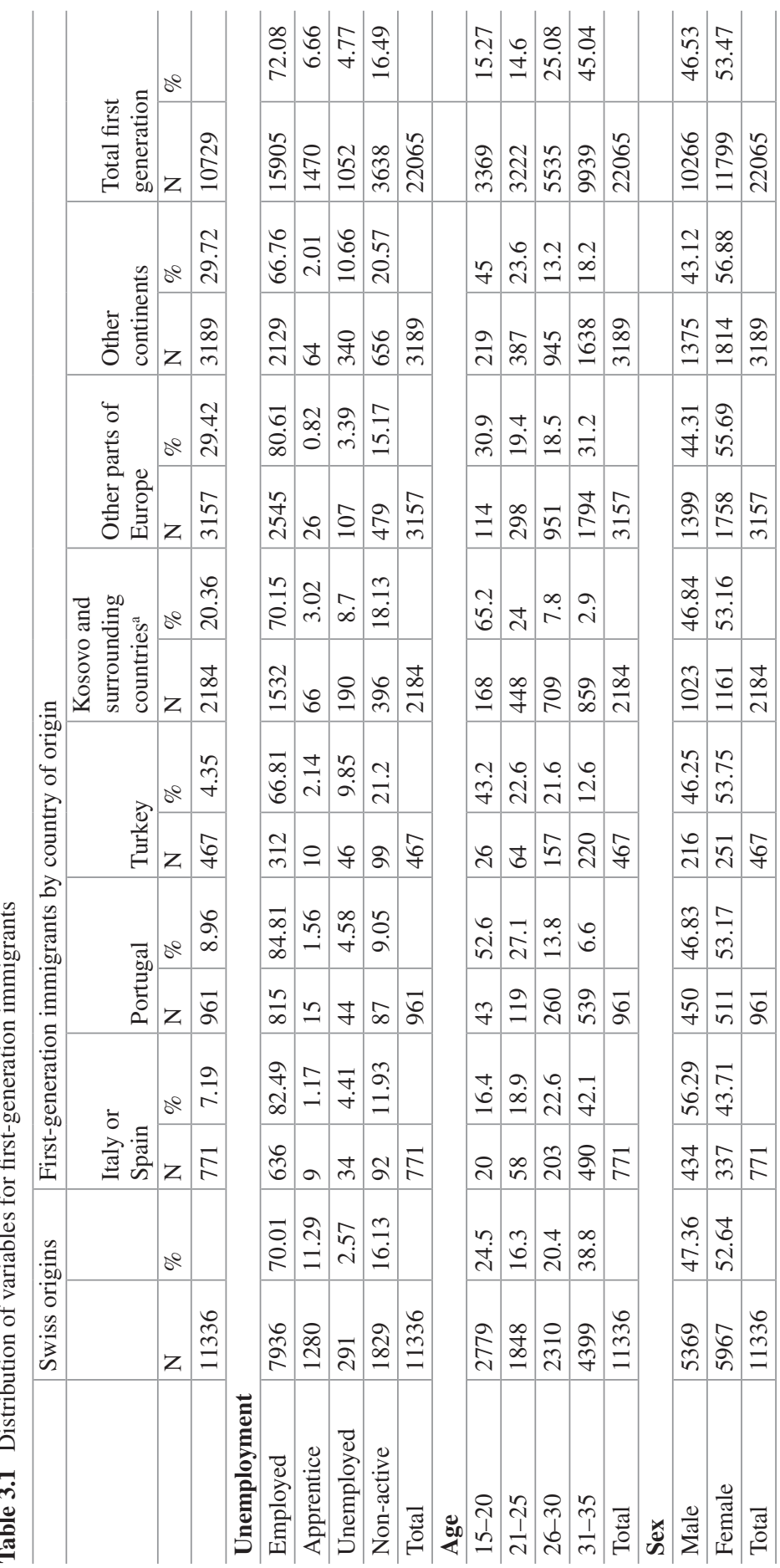




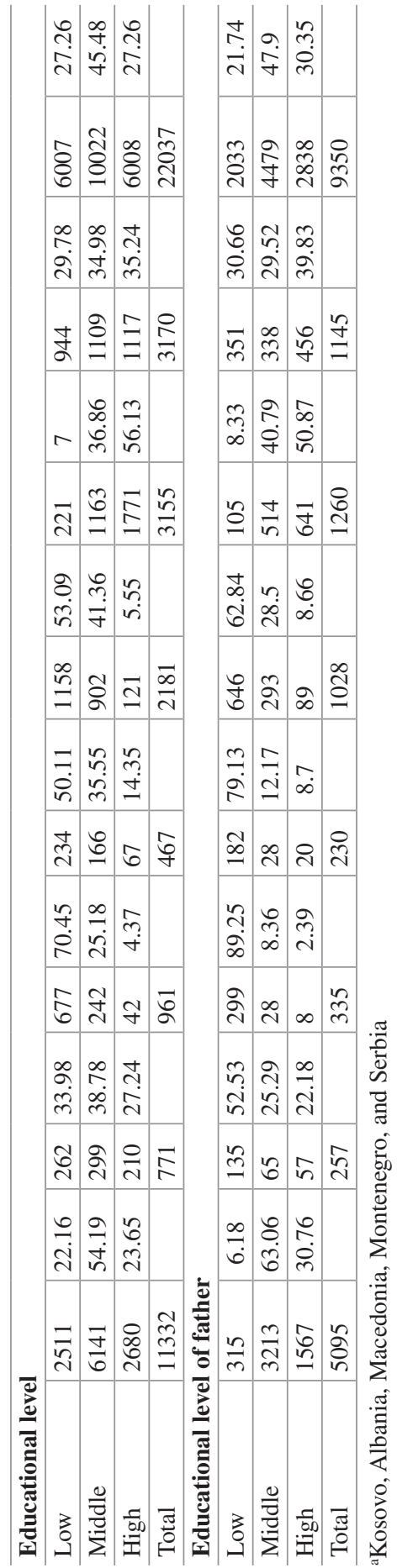




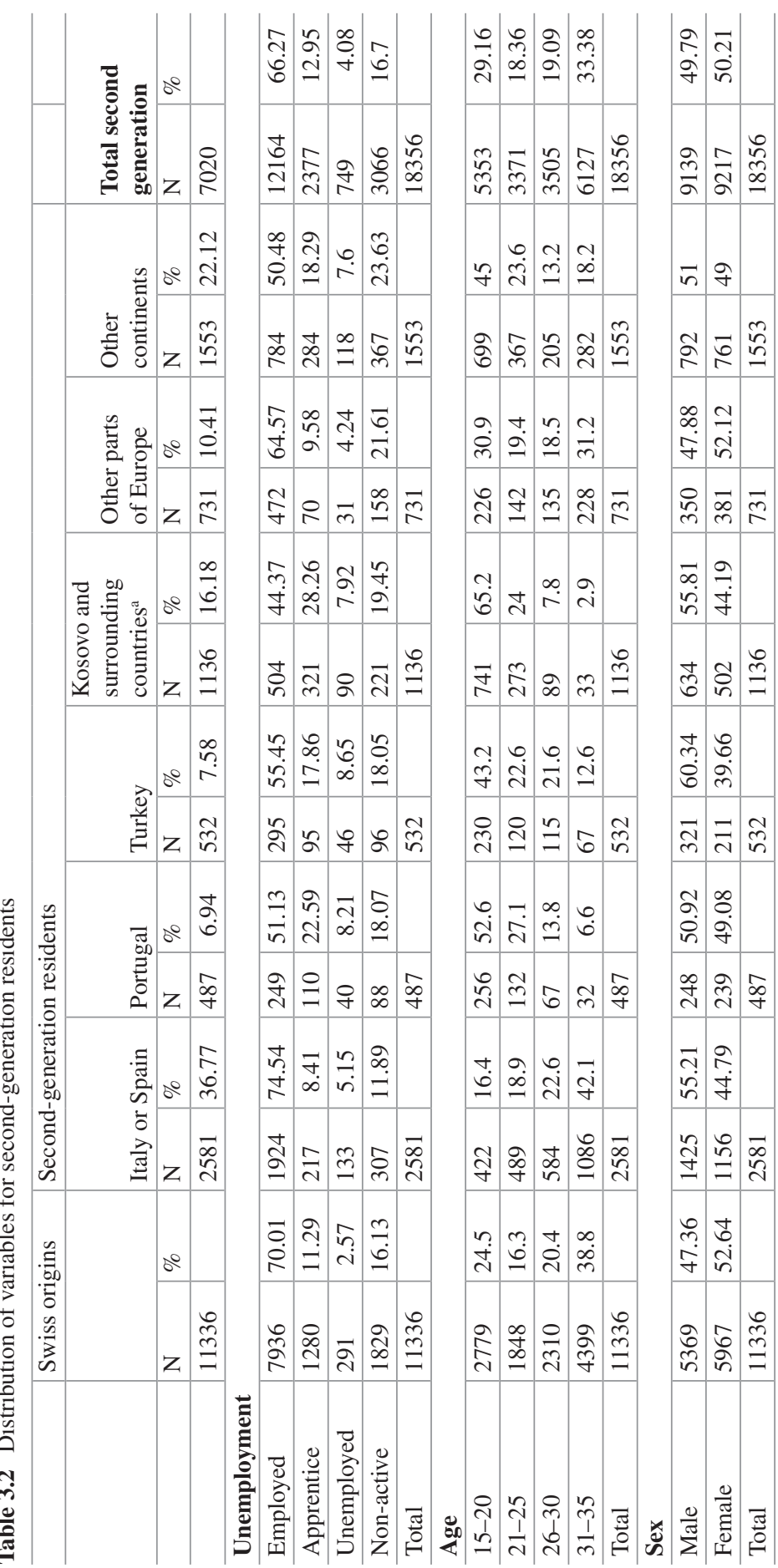




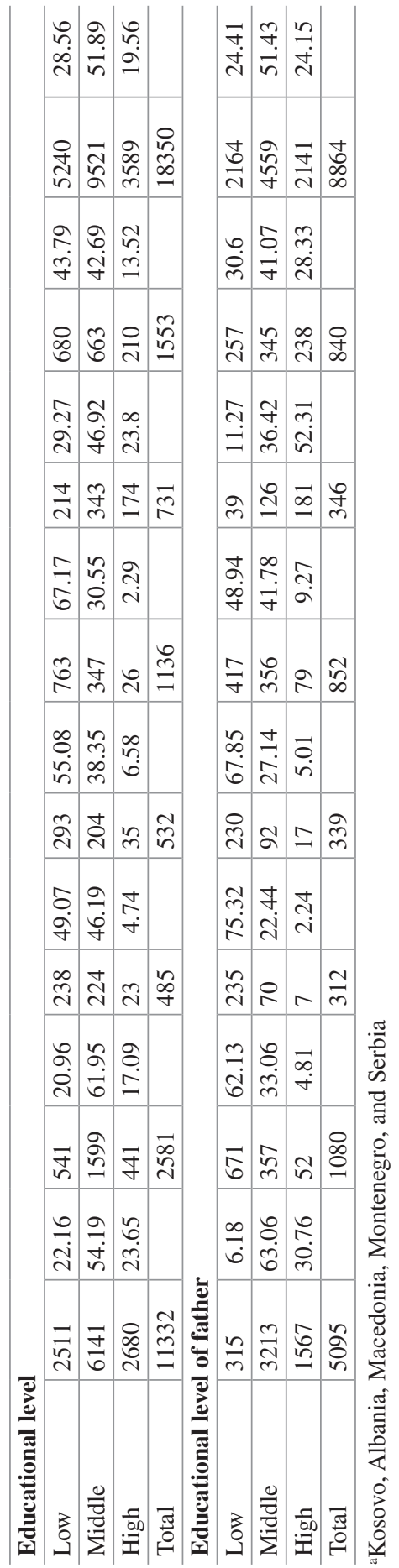




\subsubsection{Control Variables}

Age plays a significant role in employment, especially when young people access the labor market. By spending more time in the labor market, young people (1) accumulate more chances to get a job and (2) become more experienced. Therefore, it is important to control for age. Due to the trade-off between sharpness and complexity, we grouped individuals into four age categories: 15-20, 21-25, 26-30, and 31-35. As access to the labor market may be linked with male and female roles, we also controlled for sex. Finally, as the construction of our sample led to selecting individuals from different years, we had to control for a residual effect of this sampling. We coded the participation year of the survey using three groups: 2003-2005, 2006-2008, and 2009-2011.

\subsubsection{Modeling}

We started our investigation with preliminary exploratory data mining (EDM) analysis. As shown by McArdle and Ritschard (2013), EDM techniques help to highlight the combinations of variables that have predictive value. Such techniques help researchers to go beyond their research questions by discovering complex and even unexpected relations between variables. In the present case, we opted to use decision-tree modeling to detect potential interactions between covariates. Ilgen et al. (2009) already used such an approach successfully. A decision tree is a supervised learning method that uses a categorical dependent variable. This method creates a partition in the attribute space that explains the values of the dependent variable (here, the employment status). This partitioning is performed by recursively splitting data according to the different covariate values. The algorithm starts with a partition of only one element, which is called the root of the tree. At this starting point, all observations are grouped together, and nothing discriminates between them. This initial model is similar to independence in regression analysis. The algorithm thus selects the split that maximizes the gain in a user-defined quality measure (chi-squared distance, Gini entropy, etc.). After the split, the partition contains two or more elements, which are called nodes. The process is then recursively repeated on each child node. The tree's growth breaks when a stopping criterion is satisfied. Stopping criteria include minimum number of individuals in a child node, a minimum improvement in the growing criterion, and a limit on the number of levels. This procedure is very efficient for discovering underlying interrelations between covariates. We computed trees according to the Chi-squared Automatic Interaction Detection (CHAID) method (Kass 1980) using $\mathrm{R}$ software (R Core Team 2014). The CHAID method uses the Pearson chi-squared test to assess the quality of a split. We controlled the tree's growth with a significance threshold ( $p$ value) of 0.05 for both splitting variables and merging groups. We succeeded in highlighting the interaction effect by considering the variables of age, sex, respondent's educational level, and father's educational level. The corresponding tree is presented in Fig. 3.1 and discussed in Sect. 3.3. 


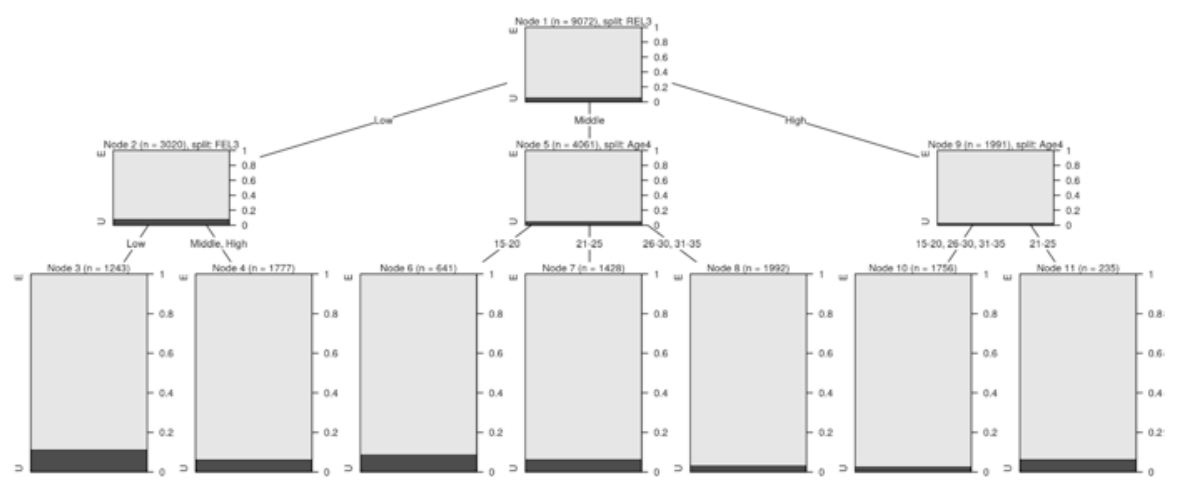

Fig. 3.1 Decision tree for the prediction of unemployment (CHAID method)

We then performed a standard logistic regression model with embedded blocks (Table 3.3). The first model assesses the impact of the country of origin on both the first and second generations; it controls for age, sex, and the year of participation in the survey. Model 2 adds the educational level to the equation. Models 3, 4, and 5 are built according to results observed with the decision tree method, which showed an interaction effect between the levels of education for the respondent and his/her father (see below). Model 3 adds the father's educational level. As this last variable produces no evidence, Model 4 assesses it without controlling for the child's educational level. Indeed, we suspect that the effect of the father's educational level is strongly connected to that of the child's educational level, making the latter variable unable to produce new, significant evidence. However, even without taking into account the child's educational level, the father's educational level has no significant global impact. Model 5 considers the previously highlighted interaction between the child's and the father's educational level.

\subsection{Results}

\subsubsection{Comments on Control Variables}

Results show that the year of participation in the survey is not significant. This indicates that the construction of our sample (taking the up-to-date employment status and corresponding values of covariates separately for each individual) did not introduce significant bias. Regarding age, youths are more affected by unemployment, as expected. A surprising finding, however, is that there is no significant difference between men and women. ${ }^{10}$

\footnotetext{
${ }^{10}$ However, further investigations, not shown here, shows that sex has a strong impact on occupational attainment.
} 


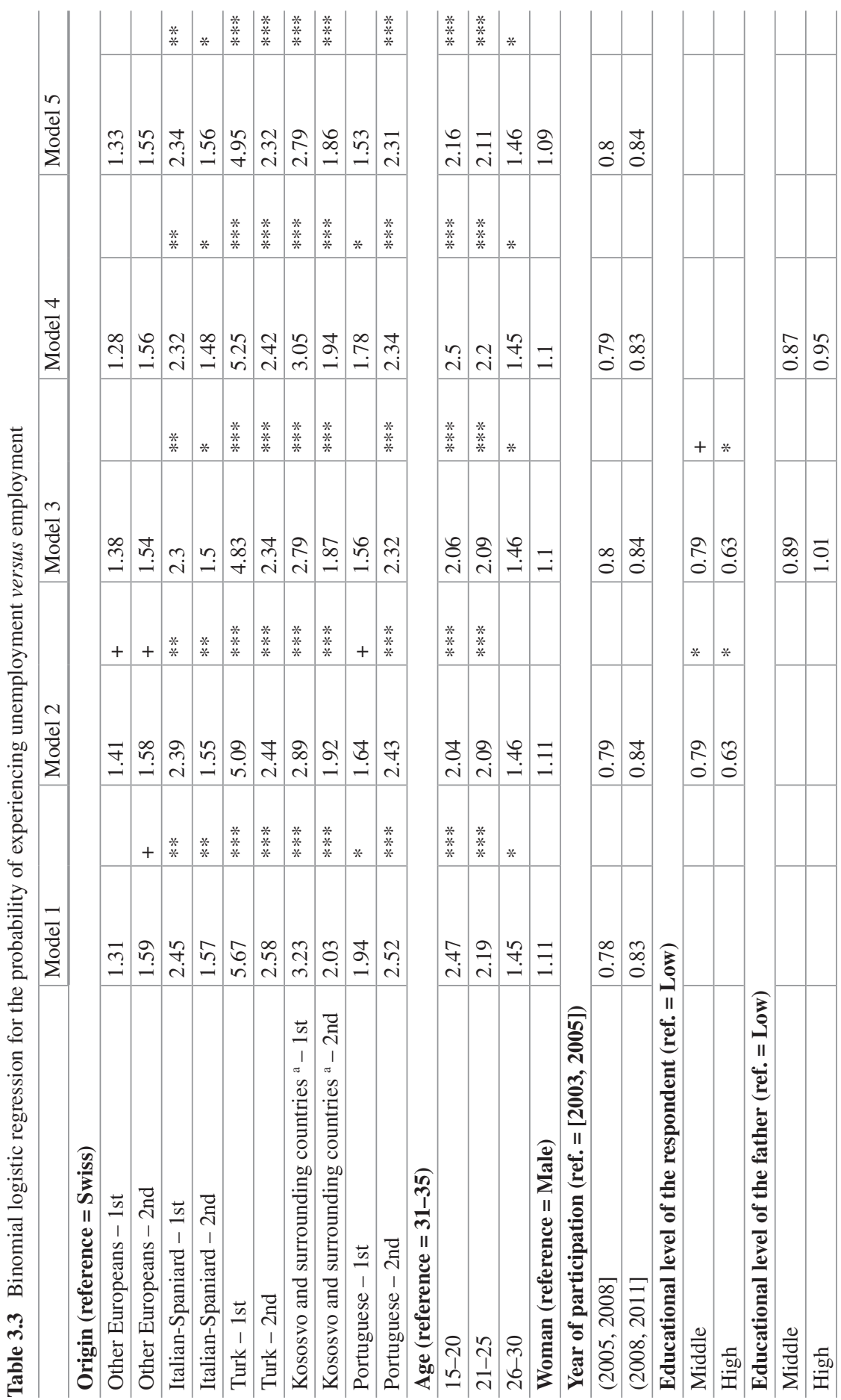




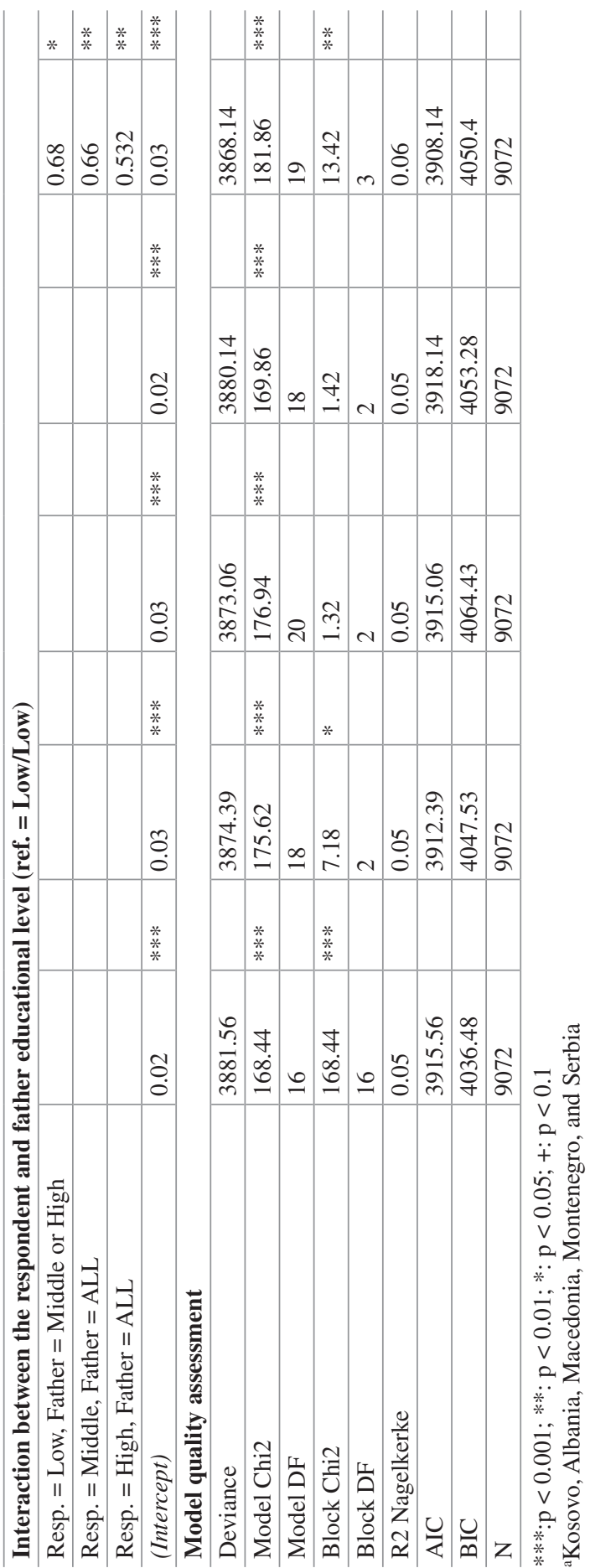




\subsubsection{Comparison of First- and Second-Generation Residents and Swiss Natives}

We observe strong disparities according to the country of origin among firstgeneration immigrants. Results show that immigrants from Turkey and Kosovo are strongly affected: The odds ratio of unemployment versus employment for secondgeneration residents of Turkish or Kosovar origin are (respectively) five and three times higher than that of Swiss natives. For those of Italian, Spanish, and Portuguese descent, the impact of origin is moderate (but significant). Such results show evidence of an assimilation process across generations, as immigrants from earlier waves succeeded more in their insertion into the labor market than did immigrants from more recent waves; the latter groups are more marginalized. Other European immigrants do not experience any more difficulties in getting a job than Swiss young adults do. Indeed, people from these other European countries come to Switzerland to enhance their professional situation more often than to escape from their country of origin.

We observe less disparity according to the country of origin for the second generation. The odds ratios for these groups vary between 1.5 and 2.5. For those of Italian, Spanish, and Kosovar origin, comparisons between the first- and secondgeneration groups show that the latter groups are less likely to be unemployed than the former groups that have the same origin. This result tends to confirm the generation-as-leveler effect. However, we observe the opposite situation in the case of the Portuguese: The odds ratio of unemployment is lower for the first generation than for the second generation. An interpretation of this result is that first-generation Portuguese immigrants have a network that facilitates getting a job. However, these jobs correspond mainly to low-skilled positions (Fibbi et al. 2010b). As children of these immigrants tend to be more educated, they do not benefit from the same efficient network.

\subsubsection{Impact of Father's Educational Level on Unemployment}

Parental educational level generally plays a role in the successful education of children. Well-educated parents can indeed provide scholarly support and advice to their children. As mentioned before, we limit our study to the father's educational level (Place and Vincent 2009). We start our analyses with a description of the preliminary decision-tree-based analysis, which highlighted interesting results concerning the impact that the father's education level has on employment (Fig. 3.1; see Sect. 2.4 for details about the method). 
First, the tree indicates that, among the different covariates we took into account, the one that best explains the lack of access to employment is the child's educational level (node 1, split: REL3). A lower educational level increases the likelihood that the child will be unemployed. The second level of the tree shows that the most relevant descriptor to explain unemployment for those with middle or high educational levels is age (nodes 5 and 9, split: Age4). In addition, for those of middle educational level, we observe an ordinal relation with the age: older respondents are more likely to get a job (nodes 6-8). Such a relation seems to be less visible for people with high educational levels (nodes 10 and 11). This could be related to there not being enough individuals to create a significant 3-class split (4061 individuals in node 5 but only 1991 in node 9 ). In the case of those in the second generation who have a low level of education, the splitting covariate is the educational level of the father (node 2, split: FEL3), which could indicate that the role of the father is more significant when young adults have a low level of education. On the other hand, the insertion of young adults with medium or high levels of education into the labor market is affected by their educational level.

To assess evidence of this interaction, model 3 of our logistic regression tests the impact of the father's educational level (Table 3.3). We observe no significant result. The variable itself is not significant. The simplest explanation (without knowing the results of the decision tree analysis from Fig. 3.1) would be that, having already controlled for the respondent's educational level, the effect of the father's educational level would not be strong enough to stand out from that of the child. Model 4 introduces the father's educational level without controlling for that of the child, but there is still no significant effect. This result seems to indicate that the impact of the father's educational level is either weak or moderated by another covariate. Model 5 considers the interaction between the father's and the child's educational levels. Using only respondents with a low level of education, this model classifies the father's educational level using a low/high coding. The results show that secondgeneration residents who have low levels of education but whose fathers have medium or high levels of education are $33 \%$ less likely to be unemployed than are those whose fathers also have a low level of education. These three models confirm that the father's educational level plays a significant role in the child's insertion into the labor market for young adults with a low educational level but a much more moderate role for those with a middle or high educational level.

\subsection{Conclusion}

Young people of foreign origin are increasingly attracting the attention of scholars and policy-makers. This is demonstrated, for instance, by the emergence of international researches such as The Integration of European Second Generation. In this chapter, we discussed the employment situation of young adults who are secondgeneration residents of Switzerland and their access to the labor market. From a 
methodological point of view, the paper advocated for the necessity of preliminary EDM analysis. Such preliminary analysis allows scholars to go beyond their research questions by discovering complex and even unexpected relations in their data. In the case of our study, this data mining showed explorative results underlying a complex relationship between the respondent's and father's levels of education. This exploratory analysis guided us to introduce an interaction effect between these two independent covariates as part of a logistic model. The results confirm this complex theory.

In more detail, our results showed a general enhancement of the labor-market situation for the second generation in comparison to the first generation. We also observed that origin-specific characteristics persist in the case of second-generation residents, although it plays a smaller role than in the case of first-generation immigrants. Furthermore, we found evidence that second-generation residents experience more disadvantages when accessing to the labor market than do Swiss natives. A strong explanatory factor for this result is the level of education. A decision-treebased exploratory analysis indicated that the father's educational level has a more significant impact on young adults with low educational levels than it does on those with middle or high educational levels. This finding can be explained by the fact that educated people are generally able to find employment on their own but that, for those with a low level of education, the father is a significant resource in helping find employment. We also show that, after controlling for social origin, age, sex, and educational level, some inequality related to ethnic origin remains unexplained. This is particularly the case for second-generation residents of Kosovar origin, who seem to suffer a substantial ethnic penalty. This last result seems to confirm Portes and Zhou's (1993) theory of segmented assimilation.

One limit of our study is its cross-sectional design. The use of a longitudinal statistical model would allow fort young people's trajectories to be studied during the transition from school to work, instead of only looking at their employment status at a given time. Furthermore, social-network analysis could provide insight into second-generation residents' accumulation of resources. By looking at the links that the second generation has established in the host country, we can collect precious information about the behaviors, resources, information flow, and power logic that are in play when these people access the professional world.

Acknowledgements This paper benefited from the support of the Swiss National Centre of Competence in Research LIVES-Overcoming Vulnerability: Life Course Perspectives, which is financed by the Swiss National Science Foundation (Grant number: 51NF40-160590).

\section{References}

Alba, R. D. (1985). Italian Americans: Into the twilight of ethnicity. Englewood Cliffs: Prentice-Hall.

Andréo, C. (2001). La transition vers l'âge adulte de jeunes marseillais issus de milieux populaires dans les années 1990. Déviance et société, 25(3), 347-365. 
Avenel, C. (2006). Quelle autonomie pour les jeunes issus de l'immigration maghrébine? In C. Bidart (Ed.), Devenir adulte aujourd'hui. Paris: L'Harmattan.

Bader, D., \& Fibbi, R. (2012). Les enfants de migrants un véritable potentiel. Neuchâtel: Forum Suisse pour l'étude des migrations et de la population.

Billari, F., \& Liefbroer, A. (2010). Towards a new pattern of transition to adulthood? Advances in Life Course Research, 15(2-3), 59-75.

Bolzman, C. (2007). Familles espagnoles et italiennes en Suisse et transition vers la vie adulte. Enfances, Familles, Générations, 6, 38-53.

Bolzman, C., Fibbi, R., \& Vial, M. (2003). Que sont-ils devenus? Le processus d'insertion des adultes issus de la migration. In H.-R. Wicker, R. Fibbi, \& W. Haug (Eds.), Les migrations et la Suisse (pp. 434-459). Seismo: Zurich.

Canales, A. (2000). Comunidades de inmigrantes. Paper presented at the La migración internacional y el desarrollo en las Américas, San José, Costa Rica.

Coleman, D. (2006). Immigration and ethnic change in low fertility countries. Population and Development Review, 32(3), 401-446.

Crul, M. (2004). The second generation in Europe. International Migration Review, 37(4), 965-986.

Crul, M. (2008). The second generation in Europe. The Experience of Second Generation Canadians. Association of Canadian Studies, 6(2), 17-20.

Crul, M., \& Mollenkopf, J. (2012). The second generation. In M. Crul \& J. Mollenkopf (Eds.), The changing face of world cities. Young adult children of immigrants in Europe and the United States. New York: Russell Sage Foundation.

Dahinden, J. (2005). Contesting transnationalism? Lessons from the study of Albanian migration networks from former Yugoslavia. Global Networks. A Journal of Transnational Affairs, 5(2), 191-208.

Farley, R., \& Alba, R. (2002). The new second generation in the United States. International Migration Review, 36(3), 669-701.

Fibbi, R., Bolzman, C., \& Vial, M. (1999). Italiennes et Espagnoles en Suisse à l'approche de l'âge de la retraite. Revue Européenne des Migrations Internationales, 15(2), 68-93.

Fibbi, R., Kaya, B., \& Piguet, E. (2004). Nomen est omen: quand s'appeler Pierre, Afrim ou Mehmet fait la différence. Forum, 3, 38-42.

Fibbi, R., Lerch, M., \& Wanner, P. (2005). Processus de naturalisation et caractéristiques socioéconomiques des jeunes issus de la migration. In R. Fibbi, M. Lerch, P. Wanner, et al. (Eds.), L'intégration des populations issues de l'immigration en Suisse: personnes naturalisés et deuxième génération (pp. 9-60). Neuchâtel: Office fédéral de statistique.

Fibbi, R., Lerch, M., \& Wanner, P. (2007). Naturalisation and socio-economic characteristics of youth of immigrant descent in Switzerland. Journal of Ethnic and Migration Studies, 33, 11211144. doi:10.1080/13691830701541655.

Fibbi, R., Lerch, M., \& Wanner, P. (2010a). School qualifications of children of immigrant descent in Switzerland. In R. Alba \& M. Waters (Eds.), New dimensions of diversity: The children of immigrants in North America and Western Europe (pp. 110-134). New York: New York University Press.

Fibbi, R., Bolzman, C., Fernandez, A., Gomensoro, A., Kaya, B., Maire, C., et al. (2010b). Les Portugais en Suisse. Bern-Wabern: Office fédéral des migrations.

Gauthier, A. (2007). Becoming a young adult: An international perspective on the transitions to adulthood. European Journal of Population, 23(3-4), 217-223.

Heath, A., \& Cheung, S. (2007). Unequal chances: Ethnic minorities in western labour markets. Oxford: Oxford University Press for the British Academy.

Heath, A., Rothon, C., \& Kilpi, E. (2008). The second generation in Western Europe: Education, unemployment, and occupational attainment. Annual Review of Sociology, 34, 211-235. 
Ilgen, M. A., Downing, K., Zivin, K., Hoggatt, K. J., Kim, H. M., Ganoczy, D., Austin, K. L., McCarthy, J. F., Patel, J. M., \& Valenstein, M. (2009). Exploratory data mining analysis identifying subgroups of patients with depression who are at high risk for suicide [CME]. The Journal of Clinical Psychiatry, 70(11), 1495-1500.

Kass, G. (1980). An exploratory technique for investigating large quantities of categorical data. Applied Statistics, 29(2), 119-127.

Kevisto, P. (2001). Theorizing transnational immigration: A critical review of current efforts. Ethnic and Racial Studies, 24(4), 549-577.

Kristen, C., Edele, A., Kalter, F., Schulz, B., Stanat, P., \& Will, G. (2011). The education of migrants and their children across the life course. Z Erziehungswiss, 14(2), 121-137.

Lagana, F. (2011). Blocked mobility or unemployment risk? Labour market transitions of natives and immigrants in Switzerland. International Journal of Comparative Sociology, 52(4), 327-349.

Levitt, P. (2004). Transnational migrants: When « home » means more than one country. Migration Policy Institute. http://www.migrationinformation.org/Feature/display.cfm?ID=261. Accessed 12 Aug 2015.

McArdle, J. J., \& Ritschard, G. (2013). Contemporary issues in exploratory data mining in the behavioral sciences. New York: Routledge.

Mens, Y. (2006). La deuxième génération bouscule l'Europe. Alternatives Internationales, 3(30), $31-32$.

Oropesa, R., \& Nancy, S. (1997). In search of the new second generation: Alternatives strategies for identifying second generation children and understanding their acquisition of English. Sociological Perspectives, 40(3), 429-455.

Perlman, J., \& Waldinger, R. (1997). Second generation decline? Children of immigrants, past and present - reconsideration. International Migration Review, 31(4), 893-922.

Place, D., \& Vincent, B. (2009). L'influence des caractéristiques sociodémographiques sur les diplômes et les compétences. Economie et Statistique, 424-425, 125-147.

Portes, A. (1994). The new second generation. International Migration Review, 28, Special Issue.

Portes, A. (1997). Immigration theory for a new century: Some problems and opportunities. International Migration Review, 31(4), 799-825.

Portes, A. (1999). La mondialisation par le bas. Actes de la recherche en sciences sociales, 129(1), $15-25$.

Portes, A., \& Zhou, M. (1993). The new second generation: Segmented assimilation and its variants. Annals of the American Academy of Political and Social Science, 530(1), 74-96.

Portes, A., Fernandez-Kelly, P., \& Haller, W. (2005). Segmented assimilation on the ground: The new second generation in early adulthood. Ethnic and Racial Studies, 28(6), 1000-1040.

R Core Team (2014). R: A language and environment for statistical computing. R Foundation for Statistical Computing, Vienna, Austria. http://www.r-project.org/

Rea, A., \& Tripier, M. (2003). Sociologie de la migration. Paris: La Découverte.

Reisel, L., Lessard-Phillips, L., \& Kasinitz, P. (2012). Entering the labor market. In M. Crul \& J. Mollenkopf (Eds.), The changing face of world cities. Young adult children of immigrants in Europe and the United States. New York: Russell Sage Foundation.

Rousseaux, E., Bolano, D. \& Ritschard, G. (2013). The Rsocialdata package: Handling survey data in R. In XXVII IUSSP International population conference, Busan, Republic of Korea, August 26th to 31st, 2013.

Settersten, R. (2005). Social policy and the transition to adulthood: Toward stronger institutions and individual capacities. In R. Settersten, J. Furstenberg, \& R. Rumbaut (Eds.), On the frontier of adulthood: Theory, research and public policy (pp. 534-560). Chicago: University of Chicago Press.

Simon, P. (2003). France and the unknown second generation: Preliminary results on social mobility. International Migration Review, 37(4), 1091-1119. 
Telhado, P., \& Tavares, L. (2000). Is schooling of migrants' children more like that of their parents, their cousins, or their neighbours? Journal of International Migration and Integration, 1(4), 443-459.

Vertovec, S. (2003). Migration and other modes of transnationalism: Towards conceptual cross -fertizilization. International Migration Review, 37(3), 641-665.

Wanner, P. (2004). Integration professionnelle des populations d'origine et de nationalité étrangères en Suisse. Revue Européenne des Migrations Internationales, 20(1), 33-45.

Open Access This chapter is licensed under the terms of the Creative Commons Attribution 4.0 International License (http://creativecommons.org/licenses/by/4.0/), which permits use, sharing, adaptation, distribution and reproduction in any medium or format, as long as you give appropriate credit to the original author(s) and the source, provide a link to the Creative Commons license and indicate if changes were made.

The images or other third party material in this chapter are included in the chapter's Creative Commons license, unless indicated otherwise in a credit line to the material. If material is not included in the chapter's Creative Commons license and your intended use is not permitted by statutory regulation or exceeds the permitted use, you will need to obtain permission directly from the copyright holder.

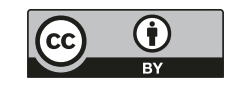

